\title{
The Madden-Julian oscillation wind-convection coupling and the role of moisture processes in the MM5 model
}

\author{
Erwan Monier - Bryan C. Weare • \\ William I. Gustafson Jr.
}

Received: 8 January 2009/Accepted: 24 June 2009/Published online: 24 July 2009

(c) The Author(s) 2009. This article is published with open access at Springerlink.com

\begin{abstract}
The Madden-Julian oscillation (MJO) produced by a mesoscale model is investigated using standardized statistical diagnostics. Results show that upper- and lowerlevel zonal winds display the correct MJO structure, phase speed $\left(8 \mathrm{~m} \mathrm{~s}^{-1}\right)$ and space-time power spectrum. However, the simulated free atmosphere moisture, outgoing longwave radiation and precipitation do not exhibit any clear MJO signal. Yet, the boundary layer moisture, moist static energy and atmospheric instability, measured using a moist static energy instability index, have clear MJO signals. A significant finding is the ability of the model to simulate a realistic MJO phase speed in the winds without reproducing the MJO wind-convection coupling or a realistic propagation in the free atmosphere water vapor. This study suggests that the convergence of boundary layer moisture and the discharge and recharge of the moist static energy and atmospheric instability may be responsible for controlling the speed of propagation of the MJO circulation.
\end{abstract}

Keywords Tropical intraseasonal oscillation . Simulation · Propagation speed - Convection . Moisture processes $\cdot$ Atmospheric instability

E. Monier $(\bowtie)$. B. C. Weare

Atmospheric Science Program, Department of Land, Air and Water Resources, University of California, Davis, CA 95616, USA

e-mail: emonier@ucdavis.edu

W. I. Gustafson Jr.

Atmospheric Sciences and Global Change Division,

Pacific Northwest National Laboratory,

Richland, WA 99352, USA

\section{Introduction}

The Madden-Julian Oscillation (MJO) is the dominant component of intraseasonal variability in the Tropics, first identified and documented by Madden and Julian (1971, 1972). Since the 1980s, the MJO has received a great deal of attention in part because of its impact on weather systems around the globe. Among others, the MJO influences the variability of rainfall in the west coast of North America (Jones 2000), affects the Indian monsoon development (Lau and Chan 1986; Madden and Julian 1994), and modulates the frequency and intensity of hurricanes in the Pacific Ocean and Caribbean Sea (Maloney and Hartmann 2000). For these reasons, the MJO is regarded as a forecast tool with great potential (Hendon et al. 2000). Furthermore, the MJO has been shown to interact with the ocean (Zhang 1996; Hendon and Glick 1997; Jones et al. 1998) and thus may influence the evolution of the El Niño-Southern oscillation (ENSO). Several simulations reveal that the westerly winds associated with the MJO had a significant role in the onset and growth of the 1997-1998 El Niño (Kessler and Kleeman 2000; Boulanger et al. 2004). These results substantiate speculations that the inadequate ENSO predictions by numerical models could be partly caused by a lack of simulation of the MJO (Zhang 2005). In addition, a medium range forecast model with poor MJO skills has systematic forecast errors during active MJO events compared to quiescent or inactive events (Hendon et al. 2000).

For all these reasons, the MJO has become over the last few decades the "Holy Grail" of tropical atmospheric dynamics and has not ceased to be a challenge for the modeling community. In the last decade, considerable work was devoted to further understand the factors that control the realism of simulated $\mathrm{MJO}$, such as convection 
parameterization, air-sea coupling or model resolution. Zhang (2005) has proposed systematic procedures with standardized diagnostics to effectively assess the quality of MJO simulations and to easily compare the efficiency of models.

The aim of this study is to use a regional model to better understand the development phase of the MJO. While the coupling between deep convection and circulation is at the center of some MJO theories, other theories rely on boundary layer processes, including moisture convergence. Therefore the MM5 model is used to diagnose the possible mechanisms controlling the unique speed of propagation of the MJO with a focus on the role of the wind-convection coupling and of the moisture processes. Such investigation is needed to better understand the inability of most general circulation model (GCM) to produce realistic MJO signals. This work will expand on that by Gustafson and Weare (2004), who conducted a series of extended simulations in order to test the ability of the fifth-generation Pennsylvania State University (PSU)National Center for Atmospheric Research (NCAR) Mesoscale Model (MM5) to replicate the Madden-Julian Oscillation. Since MM5 is a regional model, observational data is required to initialize the model and to force its boundaries. Gustafson and Weare (2004) suggest that a change of input dataset from the National Centers for Environmental Prediction (NCEP)-NCAR re-analysis (NRA) used previously to the European Centre for MediumRange Weather Forecasts (ECMWF) Re-Analysis (ERA-40) might yield significant differences in the MJO, specifically improving the erroneous OLR and altering divergence patterns. Even though the two datasets are overall very similar, some key differences could translate into a better or worse simulation of the MJO. For example, the strongest 200-hPa divergence occurs to the north of the equator in the NRA dataset while it occurs to the south of the equator in the ERA-40, for both the western Pacific and Indian Oceans (Newman et al. 2000). Furthermore, in the present study the MM5 domain is widened to include a larger part of the African Continent, which may play a role in the recharge mechanism of the MJO. Finally, the procedure introduced in Zhang (2005) is followed to better understand the shortcomings of the model and identify the possible mechanisms controlling the MJO phase speed and vertical structure.

\section{Model, data, and method}

\subsection{Model}

This project uses the MM5 version 3.4 (Grell et al. 1995), a regional model highly adaptable and capable of producing a reasonably realistic MJO (Gustafson and Weare 2004). In the previous study, a domain extending across the tropical Indian and western Pacific Oceans, approximately between $24^{\circ} \mathrm{NS}$ and $44^{\circ}-181^{\circ} \mathrm{E}$, was chosen. That domain covers the various active regions of the MJO: the conditioning and recharging phase over the western Indian Ocean, the growth over the Indian Ocean, and the full propagation over the eastern Indian Ocean and the western Pacific Ocean before the signal recedes near the date line. However, the zonal scale of the domain only allows the development of global scale wavenumbers 3 and above without crossing the west and east boundaries. This could be problematic since the MJO is associated with planetary scale wavenumber $1-2$ in the zonal winds. In addition, a domain at least half the globe in longitude is necessary to compute the full space-time spectral power which is used to isolate the planetary eastward propagation at intraseasonal time scales (see Sect. 2.3.1). Moreover, that domain does not include the east coast of Africa, which could potentially play a role in the recharge mechanism of the MJO. For these reasons, we opted in this study to extend the width of the domain to $10^{\circ}-200^{\circ} \mathrm{E}$, making it slightly wider than half the globe.

As in Gustafson and Weare (2004), the period chosen in this study totals 26 months, beginning June 11990 and ending August 31 1992, and provides two winters and a summer of 30-90 day bandpassed filtered data. The domain has a horizontal grid interval of $60 \mathrm{~km}$ and 30 vertical levels (from the surface to $10-\mathrm{hPa}$ ), 10 of these levels being below the 0.85 sigma level, in order to accurately simulate low-level stability. The physics parameterizations chosen for the model run are as follows: the Betts-Miller lagged convective adjustment scheme (Betts 1986; Betts and Miller 1986) for subscale precipitation, the five-phase (cloud drops, rain, ice, snow, and graupel) Goddard (Lin et al. 1983; Tao et al. 1989) for explicit moisture calculations, the Eta Model, MellorYamada 2.5-level scheme (Janjic 1990, 1994) for the boundary layer parameterization and the Rapid Radiation Transfer Model (Mlawer et al. 1997) for radiation. The choice of physics parameterizations is based upon analyzing a suite of 34 preliminary runs performed using MM5 version 2 on a smaller domain, running between $13^{\circ} \mathrm{S}-11^{\circ} \mathrm{N}$ and $130^{\circ}-180^{\circ} \mathrm{E}$ (Gustafson and Weare 2004). The overall criteria used to determine the final physics parameterizations are realistic wind patterns and precipitation, especially large-scale organization of precipitation and convection. Additionally, the sea surface temperatures vary in time and are based upon the ECMWF ERA-40 boundary conditions. The specific details of the choice of physics parameterization, domain grid and period for the model run can be found in Gustafson and Weare (2004). 


\subsection{Data}

The ECMWF ERA-40 (Uppala et al. 2005), chosen to initialize and force the model boundaries, is based upon 0000, 0600, 1200, and 1800 UTC data. In addition to the ERA-40, the National Oceanic and Atmospheric Administration (NOAA) interpolated outgoing longwave radiation (OLR) daily dataset (Liebmann and Smith 1996) and the Climate Prediction Center (CPC) merged analysis of precipitation (CMAP) pentad data product (Xie and Arkin 1997), on a $2.5^{\circ} \times 2.5^{\circ}$ grid like the ERA-40, serve as independent datasets for OLR and precipitation for comparing the observations with the model output. In the rest of this article, we refer to these datasets, including the ERA-40, as "observations". In addition, the various fields of the ERA-40 are used to calculate the observed moist static energy (MSE), defined as MSE $=C_{p} T+L q+g z$, where $C_{p}$ is the specific heat of air, $T$ is the air temperature, $L$ is the latent heat of condensation, $q$ is the specific humidity, $g$ is the gravitational constant, and $z$ is the geopotential height.

\subsection{Method}

The methodology used to evaluate the realism of the simulated MJO follows the procedure proposed by Zhang (2005). The analysis is done over data ranging from $20^{\circ} \mathrm{S}-$ $20^{\circ} \mathrm{N}$ and $15^{\circ}-195^{\circ} \mathrm{E}$, thus excluding the 8 grid points nearest to the boundaries. This ensures that the direct signal from the boundary conditions does not contaminate the statistics. First, the space-time power spectrum is computed to isolate the planetary scale eastward propagation at intraseaonal time scale associated with the MJO. Then, the leading modes of the MJO signal are extracted from the output model, using combined empirical orthogonal function (EOF) analysis. The leading modes are then used to identify the MJO primary features (phase speed, horizontal and vertical structure). Finally, the procedure calls for inspecting the spatial distribution and seasonal cycle. However, since the simulation provides only two winters and one summer of filtered data, the seasonality cannot be well established. Instead, the temporal and spatial variability in the observations and the model are compared. In addition, a study of the North and South boundary conditions is included to verify that the propagation and structure of the simulated MJO are not primarily driven by an MJO signal present in the meridional boundaries.

\subsubsection{Power spectrum}

Space-time power spectral analysis (Hayashi 1982) is used to separate various fields into eastward-moving and westward-moving components. When studying the MJO, this analysis should reveal the existence of an eastward propagating signal for zonal wavenumbers $1-3$ and periods between 30 and 90 days. This analysis is a preliminary test to identify the presence of an eastward propagating signal and to establish the separation of an intraseaonal signal from the lower-frequency power. For this reason, a spacetime power spectrum should be computed using unfiltered data. Following Hayashi's method, the space complex Fourier coefficients are first computed using a forward Fourier transform in space. Since the model domain is only half the globe in longitude, we reconstruct the whole globe in order to compute the Fourier coefficients for all the global scale wavenumbers. The missing hemisphere is filled for any variable $f(x)$ by $f(x)=f\left(x+180^{\circ}\right)$ when computing the complex Fourier coefficients for even wavenumbers and filled by $\mathrm{f}(\mathrm{x})=-\mathrm{f}\left(\mathrm{x}+180^{\circ}\right)$ for odd wavenumbers. Even though observations are available for the whole globe, the same methodology is used on the observations for consistency in comparison with the simulation. This analysis yields similar results to previous observational studies (see Sect. 3a).

\subsubsection{Data filtering}

To isolate the MJO in time, a 30-90 day Lanczos bandpass filter (Duchon 1979) with 151 weights is chosen. The number of weights is a compromise between the quality of the filter and the amount of the resulting filtered data. This choice of filter provides two winters of filtered data with the intervening summer while running a 22-month simulation. This Lanczos bandpass filter also allows consistency between the results presented in this paper and the previous work by Gustafson and Weare (2004).

\subsubsection{Combined EOF analysis}

In order to extract the MJO signals in the observations and the model output, an EOF analysis of combined 30-90 day bandpass filtered OLR and zonal winds at 850 and 200-hPa (further on referred as, respectively, U850 and U200) is employed, following Wheeler and Hendon (2004). Beforehand, each field is averaged over $20^{\circ} \mathrm{S}-20^{\circ} \mathrm{N}$ and then normalized by the square root of its domain mean variance, so that each field contributes equally to the explained variance of the EOFs. This method produces a pair of leading modes that are well separated from the rest according to Zhang and Hendon (1997) extension of the North et al. (1982) "Rule of thumb". According to Wheeler and Hendon (2004), using EOFs of combined fields of equatorially averaged zonal winds and OLR isolates more effectively the MJO signal than a single level field EOF analysis. The combined EOF analysis has also the advantage that it takes into account the 
wind-convection coupling associated with the MJO without the complexity of a singular value decomposition (SVD) analysis. The principal components (PCs) of the leading modes are used to reconstruct (through linear regression) various fields, in both the re-analysis and model output, in order to isolate the MJO signal (Zhang et al. 2006). The reconstructed variables, referred to as "MJO variables" are then examined to identify the horizontal and vertical structure of the observed and simulated MJO. One disadvantage of the combined EOF analysis is that the computed MJO leading modes do not include any seasonal migration with latitude, and only the eastward propagation can be investigated using the "MJO variables".

\subsubsection{MJO index}

The leading modes obtained from the combined EOF analysis are also used to create an MJO index. This index is computed in the following way, where $t$ is the time in days:

$\operatorname{Index}(t)=\operatorname{PC} 1(t)+\operatorname{PC} 2(t+$ lag $)$

where lag is the lag of maximum correlation between PC1 and PC2 (11 days for the observations and 12 days for the model output). The index is a linear combination of the first two leading modes PCs where the lag between PC1 and PC2 is taken into account. This index is associated with a spatial structure similar to the first EOF, hence explaining a large percentage of the MJO variance.

\subsubsection{Phase speed}

The eastward propagation and phase speed of the MJO signal are evaluated using lag-correlations of the MJO index with equatorially averaged filtered variables. This analysis describes the propagation of dynamical and thermodynamical fields, as well as their phase relationships. The speed of propagation can then be obtained by evaluating the slope of the correlation pattern. However, since the phase speed of the MJO varies from event to event and during the life cycle of one given event (Hendon and Salby 1994), it would be futile to compute an exact phase speed over the whole domain. Instead, the slope of the overall correlation pattern is compared to typical phase speeds associated with the MJO theory.

\subsubsection{Horizontal and vertical structure}

The horizontal structure of the MJO is investigated using horizontal composites of $\mathrm{MJO}$ variables for times when the MJO index is 1 standard deviation above its mean. Similarly, composites of zonal/height cross sections of equatorially averaged MJO variables are generated to study the vertical structure of the MJO signal. A time-lag can be applied in order to center the various features in the horizontal and vertical structure within the domain so they can then be examined in their entirety.

\subsubsection{Spatial and temporal distribution}

Hovmöller diagrams of bandpass filtered variables for the observations and the model output are used to identify the spatial and temporal distribution of the MJO. Since Hovmöller diagrams can be cumbersome to analyze, correlations between the model output and the observations along the time axis as well as along the longitude axis are calculated. These correlations provide insight into the accurate simulation of the seasonality of the MJO. They also help identify regions where, and time periods when, the model is efficient or fails to reproduce the observed MJO signal.

\section{Results}

\subsection{Climatology}

Before exploring the MJO features of the model, it is important to verify the model climate in order to determine if the MJO signal simulated by MM5 develops in a realistic background state. Figure 1 shows the 2-year mean (from 1 August 1990 to 31 July 1992) of 850-hPa winds and the annual mean precipitation. Contrary to Gustafson and Weare (2004) where the model introduces an easterly wind bias of approximately $2 \mathrm{~m} \mathrm{~s}^{-1}$ at $850-\mathrm{hPa}$, this simulation presents a $1 \mathrm{~m} \mathrm{~s}^{-1}$ westerly bias over the whole domain. The model and the observed wind patterns agree well over most of the domain, with stronger winds away from the Equator, westerlies over the Indian Ocean north of the equator, and easterlies elsewhere. Yet, the model shows westerlies over the southern and eastern Pacific Ocean, near the boundaries, where the observations present strong easterly winds. Overall these differences are small since they are within the $2-4 \mathrm{~m} \mathrm{~s}^{-1}$ differences between the NRA and ERA re-analyses (Annamalai et al. 1999). The model output and the observations show maxima in precipitation over the Indian Ocean and Pacific Ocean with a local minimum near the equator in the Pacific, which is associated with of a double intertropical convergence zone (ITCZ). The model precipitation is too weak over the Indian Ocean and over the northern branch of the ITCZ in the Pacific but too strong over the southern branch. These errors are within the range of errors exhibited by the general circulation model (GCM) simulations presented in the latest Intergovernmental Panel on Climate Change (IPCC) report (Randall et al. 2007). Notwithstanding, a major difference between the model output and the observations 

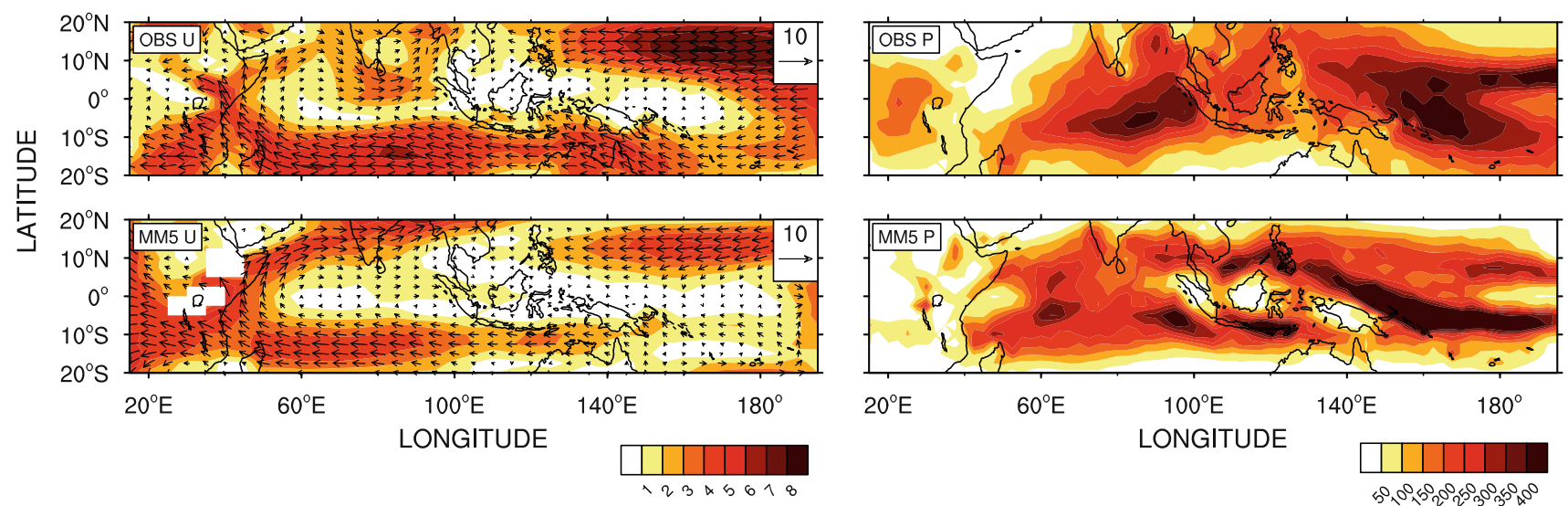

Fig. 1 Two-year mean of 850-hPa wind and annual mean precipitation for the observations and the model output. Vectors indicate wind direction, are scaled with respect to the reference magnitude,

and are plotted for every other grid point in the longitude direction. Shading represents wind magnitude $\left(\mathrm{m} \mathrm{s}^{-1}\right)$ and precipitation $(\mathrm{cm})$ as indicated by the label bars

is the absence of precipitation over the islands of Indonesia and Papua New Guinea in the MM5 model. This result is quite different from the IPCC report where GCMs show a wet bias in annual-mean precipitation over Indonesia and Papua New Guinea (Randall et al. 2007). Overall, the model errors are within the differences between the various available observational datasets and the average GCM simulation in the IPCC comparison.

\subsection{Eastward propagation}

The space-time power spectra of $20^{\circ} \mathrm{S}-20^{\circ} \mathrm{N}$ averaged U850 and OLR are presented in Fig. 2. The main features of the observations are very similar to those shown by Salby and Hendon (1994). However, it is important to note that the ratios of eastward to westward power shown in Table 1 are much greater than that shown in Zhang et al. (2006). This is easily explained by the data reconstruction methodology used here since it emphasizes the power of the Eastern Hemisphere where the MJO signal is the strongest. The MJO characteristics in the zonal winds are well reproduced by the model, especially the stronger eastward propagating power and the intraseasonal frequency band well separated from the lower frequencies. However, the model output zonal winds display a weaker ratio of eastward to westward power (Table 1) and a slightly more dominant wavenumber 1 (Fig. 2) than for the observations. In addition, Table 1 shows that the model OLR, 850-hPa specific humidity (Q850) and precipitation (P) do not demonstrate any obvious eastward propagation. Thus this analysis reveals that an intraseasonal planetaryscale eastward propagating signal is present in the model upper- and lower-level zonal winds, but is not present in the OLR, precipitation and in the free atmosphere lowerlevel moisture. Yet, there seems to be a clear eastward propagating signal in the boundary layer moisture field

(Q1000) and moist static energy (MSE1000), suggesting that moisture processes in the boundary layer and the free atmosphere have very different mechanisms. Similarly to Kemball-Cook and Weare (2001), a moist static energy instability index (MSEII) is constructed by taking MSE(1,000-hPa) minus MSE(300-hPa). This index measures the tropospheric instability and can be useful to assess the instability as a control mechanism for the MJO propagation characteristics. Indeed, the space-time power spectral analysis of the MSEII demonstrates that the model reproduces very well the intraseasonal eastward propagation of the instability that is present in the observations. In addition, the ratios of eastward to westward power for the meridional lateral boundaries show that the eastward propagating signals are weaker at the boundaries than within the model domain in all variables but the MSEII. This is especially true in the zonal winds which present very little eastward propagating signal.

\subsection{Extraction of the leading modes}

Figure 3 presents the zonal structure of the first two EOFs of combined bandpass filtered U850 and U200, and OLR, averaged over $20^{\circ} \mathrm{S}-20^{\circ} \mathrm{N}$. For the observations, the leading pair of combined EOFs explains more than $60 \%$ of the total explained variance, making them well separated from the remaining EOFs based on the criteria of North et al. (1982) (the third EOF explains only $8.7 \%$ of the variance) and they are similar to the analysis of Wheeler and Hendon (2004). The corresponding principal components (PCs) are in quadrature and the first PC leads the second one by 11 days with a correlation of $84.0 \%$. This implies a periodicity of 44 days, consistent with the theory. Thus the leading EOF pair represents the main structure and eastward propagation of the MJO. Furthermore, the PCs associated with the leading modes exhibit moderate active MJO 
Fig. 2 Space-time power spectra of the $20^{\circ} \mathrm{S}-20^{\circ} \mathrm{N}$ averaged U850 and OLR. Contour intervals are 6 from 3 to 15 and 10 from 15 and beyond for U850, and 150 from 100 to 1,000 and 400 from 1,000 and beyond for OLR. Units are $\mathrm{m}^{2} \mathrm{~s}^{-2}$ day for U850 and $\mathrm{W}^{2} \mathrm{~m}^{-4}$ day for OLR. Note that the space-time power spectrum for the model output OLR is weak compared to the observations and therefore multiplied by 3 to keep a consistent contour scheme

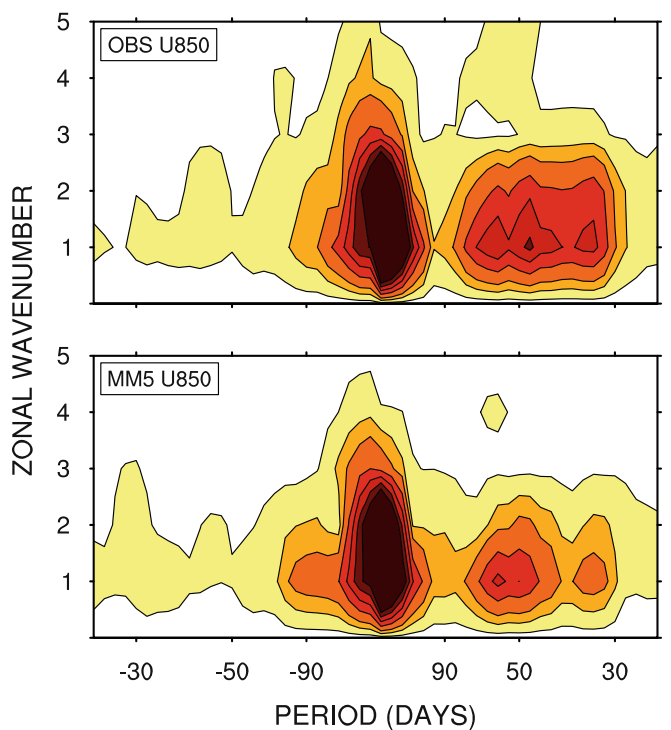

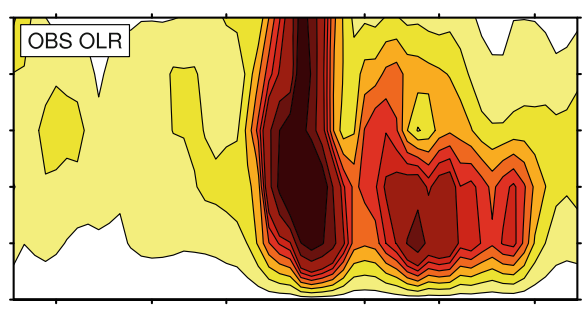

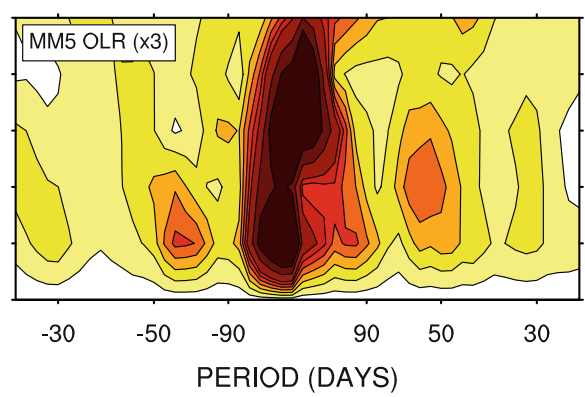

Table 1 Ratio of intraseasonal power for U850, U200, Q1000, Q850, OLR, P, MSE1000 and MSEII

\begin{tabular}{lllllllll}
\hline & U850 & U200 & Q1000 & Q850 & OLR & P & MSE1000 & MSEII \\
\hline Observations & 6.8 & 6.1 & 3.4 & 3.6 & 6.5 & 3.7 & 3.2 & 3.6 \\
Model output & 3.4 & 4.3 & 1.6 & 0.9 & 1.1 & 1.1 & 2.7 & 3.7 \\
N/S boundaries & 1.5 & 1.3 & 1.9 & 2.0 & 2.6 & 1.1 & 1.9 & 6.9 \\
\hline
\end{tabular}

Intraseasonal powers are calculated within the window of 30-90 day periods at zonal wavenumber 1 for U850, U200, Q1000, Q850, MSE1000 and MSEII, and zonal wavenumbers $1-2$ for OLR and P

events during the fall 1990, spring 1991 and strong events during winter and spring 1992. These two PCs are used to construct an MJO index. Weare (2006) warns about doing composite analysis using a reference dataset which focuses on convection centered over the Maritime Continent. The composites would then present an amalgam of the different properties of the MJO over the Indian and Pacific Oceans. Since the index is associated with a pattern of convection similar to that of the first EOF, centered east of the Maritime Continent, this issue should be avoided.

Like the observations, the model output has a dominant pair of leading EOFs, explaining approximately $50 \%$ of the explained variance (while the third EOF accounts for just $10 \%$ of the variance). These leading modes display wind patterns consistent with the observations. However, the associated enhanced convective center is not reproduced. Nonetheless the correlations between the first pairs of PCs of the observations and the model are high, $87.9 \%$ for the first PC and $92.1 \%$ for the second. This implies strong similarities in the MJO circulation and its propagation between the ERA-40 re-analysis and the model. In addition, the model output PCs show a maximum correlation $(81.8 \%)$ for a lag of 12 days.

\subsection{Phase speed}

The phase speed and the eastward propagation of the MJO signal are investigated through lag-correlations, at all longitudes, of the equatorially averaged U850, U200, Q850, OLR and MSEII upon the MJO index (Fig. 4). The observations show a coherent organization and consistent eastward propagation in all fields with a characteristic phase speed around $8 \mathrm{~m} \mathrm{~s}^{-1}$, typical of the MJO (Hendon and Salby 1996; Lin et al. 2006). It is worthy of note that the phase speeds of the NOAA OLR and the CPC precipitation (not shown) display good agreement with the ERA-40, thus demonstrating consistency in the observational datasets used in this study.

The model output shows very good agreement with the ERA-40 re-analysis in the eastward propagation of the zonal winds, both at upper- and lower-levels. The propagation is smooth and well organized with a realistic MJO phase speed over the whole domain. However, as expected from the previous results, the MM5 model output lacks a clear organization and a realistic eastward propagation in Q850 and OLR. While there are indications of eastward propagation in the OLR, it does not have a realistic MJO 
Fig. 3 Spatial structures of EOFs 1 and 2 of the combined analysis of 30-90 day bandpass filtered, $20^{\circ} \mathrm{S}-20^{\circ} \mathrm{N}$ averaged, OLR (solid lines), U850 (dashed lines) and U200 (dotted lines)

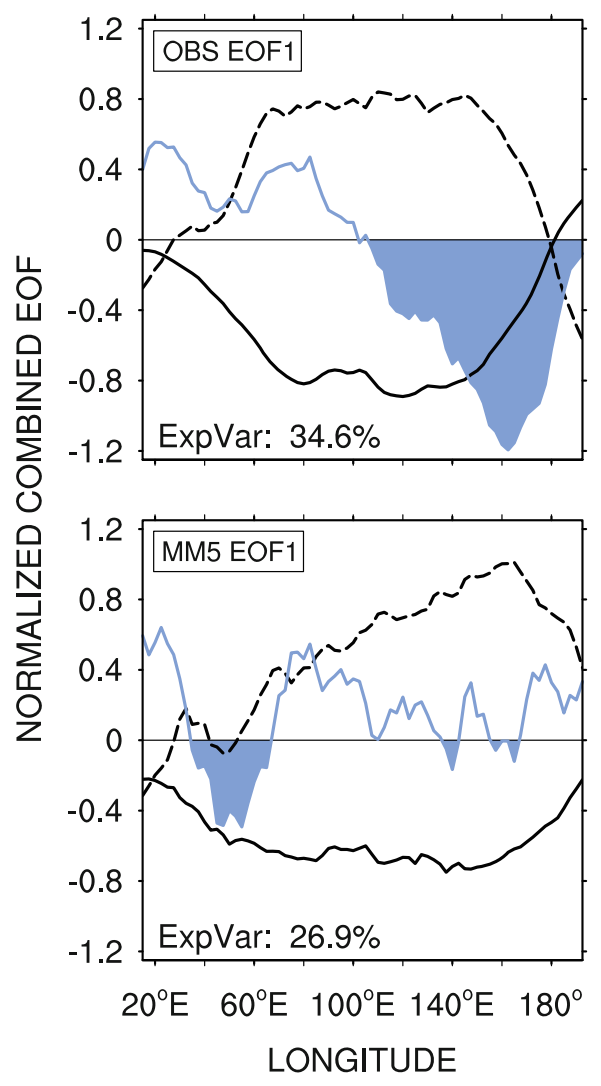

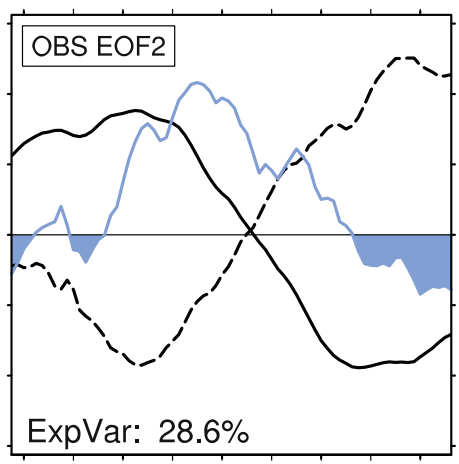

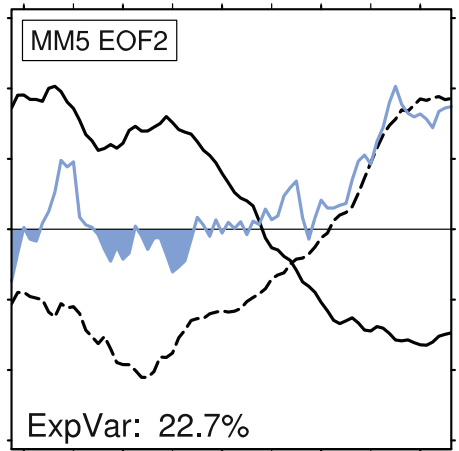

$20^{\circ} \mathrm{E} \quad 60^{\circ} \mathrm{E} \quad 100^{\circ} \mathrm{E} 140^{\circ} \mathrm{E} \quad 180^{\circ}$ phase speed and it is too intermittent. Yet, the MSEII in the model displays a clear eastward propagation with a realistic phase speed, especially over the Indian Ocean. Like for the observations, the MSEII does not propagate as smoothly as the zonal wind and exhibits some discontinuity between the Maritime Continent and the western Pacific Ocean. Overall, only the model output winds and stability index show a clear and realistic MJO propagation.

The analysis of the meridional boundaries reveals the absence of coherent eastward propagation in phase with the propagation seen in the zonal winds for both the observations and the model output. Moreover, the absence of propagation is similar in the lower-level moisture and OLR. Only the MSEII presents a realistic propagation speed around $8 \mathrm{~m} \mathrm{~s}^{-1}$ over the whole latitudinal domain. This result strongly suggests that the realistic aspects of the MJO in this model are not dictated by the meridional boundary input data.

\subsection{Horizontal and vertical structure}

The horizontal and vertical structure of the MJO signal are investigated using composites of various $\mathrm{MJO}$ variables associated with the MJO index for a lag of -10 days in order to center the various MJO features within the domain. The horizontal composites (Fig. 5) describe the latitudinal distribution of the signal, especially the discrepancies between the Equator and the regions closer to the boundaries, while the vertical composites (Fig. 6) provide insight into the differences in the vertical structure of the MJO as it evolves. The horizontal and vertical structure of the simulated MJO winds agree well with the observations. The MJO winds exhibit the first baroclinic mode in the troposphere as well as a distinct zonal asymmetry, with lowerlevel convergence and upper-level divergence. However, the convective center, diagnosed from the OLR, located slightly to the west of the upper-level divergence, seen in the observations (Sperber 2003; Kiladis et al. 2005), is not reproduced in the model. Instead some deep convection is evident around the dateline and away from the Equator, far east of the upper-level divergence. Figures 5 and 6 also display a fundamental large-scale feature observed in the MJO: positive moisture anomalies are present near and to the east of the convective center while a rapid drying, associated with negative moisture anomalies, occurs immediately to the west (Weare 2003). This dry/moist pattern is partly reproduced by the model in the boundary layer, but it is weak and noisy in the free troposphere. In addition, the moisture signal above $500-\mathrm{hPa}$ in the model is very insubstantial, except around the dateline where positive moisture anomalies coincide with the simulated convective center and where the observations show weak negative anomalies. This suggests that the inability of the model to reproduce the correct location of the deep 


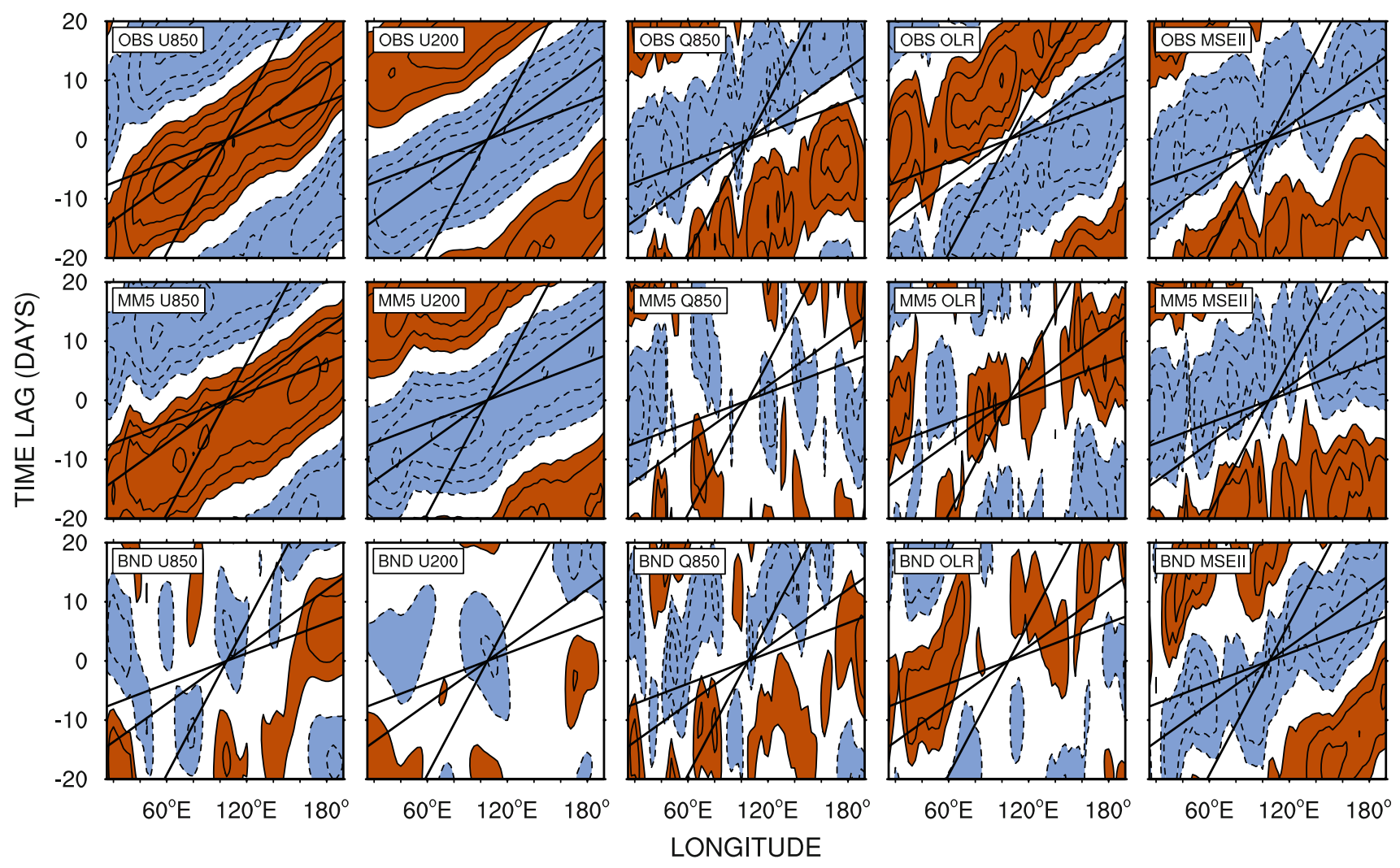

Fig. 4 Lag-correlations of the 30-90 day bandpass filtered, $20^{\circ} \mathrm{S}-$ $20^{\circ} \mathrm{N}$ averaged, U850, U200, Q850, OLR and MSEII upon the MJO index. Contour interval is 0.2 and negative contours are dashed. Dark (light) shading denotes anomalies greater than 0.2 (less than -0.2). The three thick lines correspond to eastward phase speed of 3,8 , and $15 \mathrm{~m} \mathrm{~s}^{-1}$ respectively convection is a result of a poor simulation of the upperlevel moisture. Furthermore, the vertical structure of the observed MJO MSE is similar to that of the observed MJO specific humidity, indicating that the MSE is strongly dominated by the moisture term. On the other hand, the model output MJO MSE composite displays a similar pattern to its observational counterpart, though weaker and noisier. Overall, the moist static energy shows lower-level positive anomalies building upward in the troposphere ahead of the convective center and sharp negative anomalies just west of the convection. The associated composites of MJO MSEII for the observations and the model output agree well with each other. They feature positive and negative anomalies, respectively to the east and west of the lower-level convergence, representing an unstable atmosphere ahead of the convective center and a stable troposphere after the convection has passed.

Finally, the vertical structure of the MJO signal on the meridional boundaries reveals that the zonal winds lack the first baroclinic mode, which is an essential feature of the MJO. The MJO signal in the moisture and deep convection are both noisy and lack the zonal wavenumber 1 structure. The moisture also lacks a consistent lower-level moistening building upward into the troposphere ahead of the convection. Meanwhile, the MSE vertical structure shows a signal above $500-\mathrm{hPa}$, which seems to be solely responsible for the strong signal in the MSEII. The MSE signal is noisy and inconsistent in the boundary layer. Overall, a realistic and coherent MJO signal is absent from the meridional boundaries in the winds, moisture and MSE, especially at lower-levels.

\subsection{Spatial and temporal distribution}

Figure 7 shows Hovmöller diagrams of the equatorially averaged bandpass filtered 200-hPa zonal winds. It reveals that the observations and model output are very similar, with the same relative strength and a strong seasonal variability. MJO events are clearly identifiable during the boreal fall of 1990, the spring and early summer of 1991 and the winter and spring of 1992. Outside these time periods, the organization, the power and the propagation of the signals are weak or non-existent. Longitudinal correlations at all times and temporal correlations at all longitudes between Hovmöller diagrams of the model output and the observations for U200, U850, Q850, OLR and 

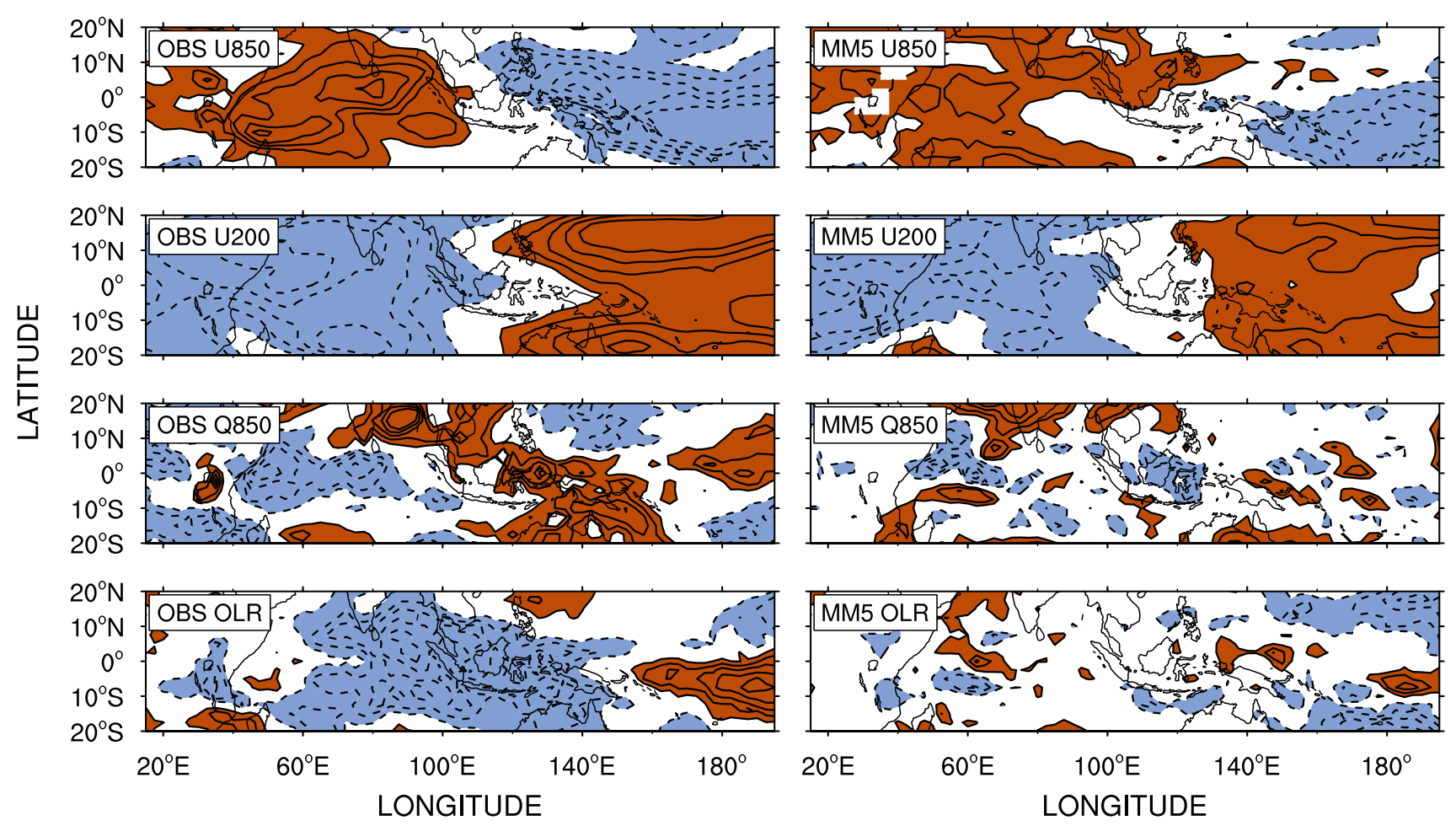

Fig. 5 Composite of MJO U850, MJO U200, MJO Q850 and MJO OLR associated with the MJO index for a lag of -10 days. MJO U850, MJO U200, MJO Q850 and MJO OLR are respectively

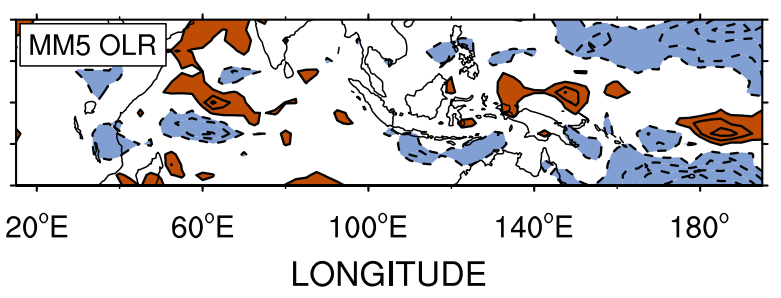

normalized by $2.0 \mathrm{~m} \mathrm{~s}^{-1}, 4.0 \mathrm{~m} \mathrm{~s}^{-1}, 0.7 \mathrm{~g} \mathrm{~kg}^{-1}$ and $15 \mathrm{~W} \mathrm{~m} \mathrm{~W}^{-2}$. Contour interval is 0.2 and negative contours are dashed. Dark (light) shading denotes anomalies greater than 0.2 (less than -0.2)

MSEII are presented in Fig. 8. This analysis reveals high correlations for U200 and U850 with a mean temporal correlation over all longitudes of 85.4 and $77.1 \%$ respectively, and a mean longitudinal correlation over all times of 79.2 and $64.8 \%$ respectively. As expected, the correlations are weaker over the Maritime Continent than over the Indian and Pacific Oceans. They are also weaker during inactive MJO events than during strong MJO events. The OLR and Q850 present poor overall correlations, with mean temporal and longitudinal correlations close to zero for OLR and close to $15 \%$ for Q850. It should be noted that the temporal correlations of the free atmosphere lowerlevel moisture are significantly higher west of the Maritime Continent (42\% as a mean) than to the east of the Indian Ocean (close to zero). This demonstrates the significant impact of the Maritime Continent on the simulation of the MJO signal, especially in the moisture field. In addition, the correlations of the OLR and Q850 are clearly higher over the African Continent, which is most likely due to the limited influence of the West boundary condition. Finally, correlations for MSEII are higher than for OLR and Q850 but weaker than for the winds (mean temporal and longitudinal correlations of 55.5 and $35.0 \%$ respectively). This analysis indicates that the model is able to reproduce the conditional instability over the whole domain better than the moisture field or the deep convection.

\section{Discussion and conclusion}

The analysis of the MM5 output reveals that the model simulates accurately the main dynamical features of the MJO circulation despite the lack of MJO-related deep convection. The simulated MJO signal in the zonal winds presents the correct intraseasonal and planetary-scale eastward propagation at a realistic phase speed. In addition, its horizontal and vertical structure and its temporal variability are well reproduced. While the simulation contains some convection and precipitation, it is not well related to the MJO. A potential factor explaining the lack of MJO wind-convection coupling is the poor simulation of the free atmosphere moisture field, especially above 500-hPa. However, even though there is no evidence of a clear MJO signal in the free atmosphere water vapor, the moisture in the boundary layer displays a clear MJO signal with the proper structure. This demonstrates that moisture processes are in general agreement with the frictional wave-CISK theory (Salby et al. 1994). Since the moist static energy is strongly driven by moisture changes at lower-levels (Kemball-Cook and Weare 2001), it is not surprising to see a strong MJO signal in MSE in the boundary layer. The equally strong MSE signal in the free troposphere seems to indicate that the influence of the temperature term in the model MSE is stronger than expected. A possible 
Fig. 6 Composite of the zonal/ height cross sections of MJO U, MJO Q and MJO MSE averaged over $20^{\circ} \mathrm{S}-20^{\circ} \mathrm{N}$ associated with the MJO index for a lag of -10 days. MJO U, MJO Q and MJO MSE are respectively normalized by $2.0 \mathrm{~m} \mathrm{~s}^{-1}$, $0.2 \mathrm{~g} \mathrm{~kg}^{-1}$ and $600 \mathrm{~J} \mathrm{~kg}^{-1}$. Contour interval is 0.2 and negative contours are dashed. Dark (light) shading denotes anomalies greater than 0.2 (less than -0.2). The associated composites of MJO OLR and MJO MSEII averaged over $20^{\circ} \mathrm{S}-20^{\circ} \mathrm{N}$ are shown, respectively, at the top in $\mathrm{W} \mathrm{m}{ }^{-2}$ and at the bottom in $\mathrm{J} \mathrm{kg}^{-1}$. Note that the MJO MSE and MSEII for the MM5 model output are weak compared to the observations and therefore multiplied by 2 to keep a consistent contour scheme

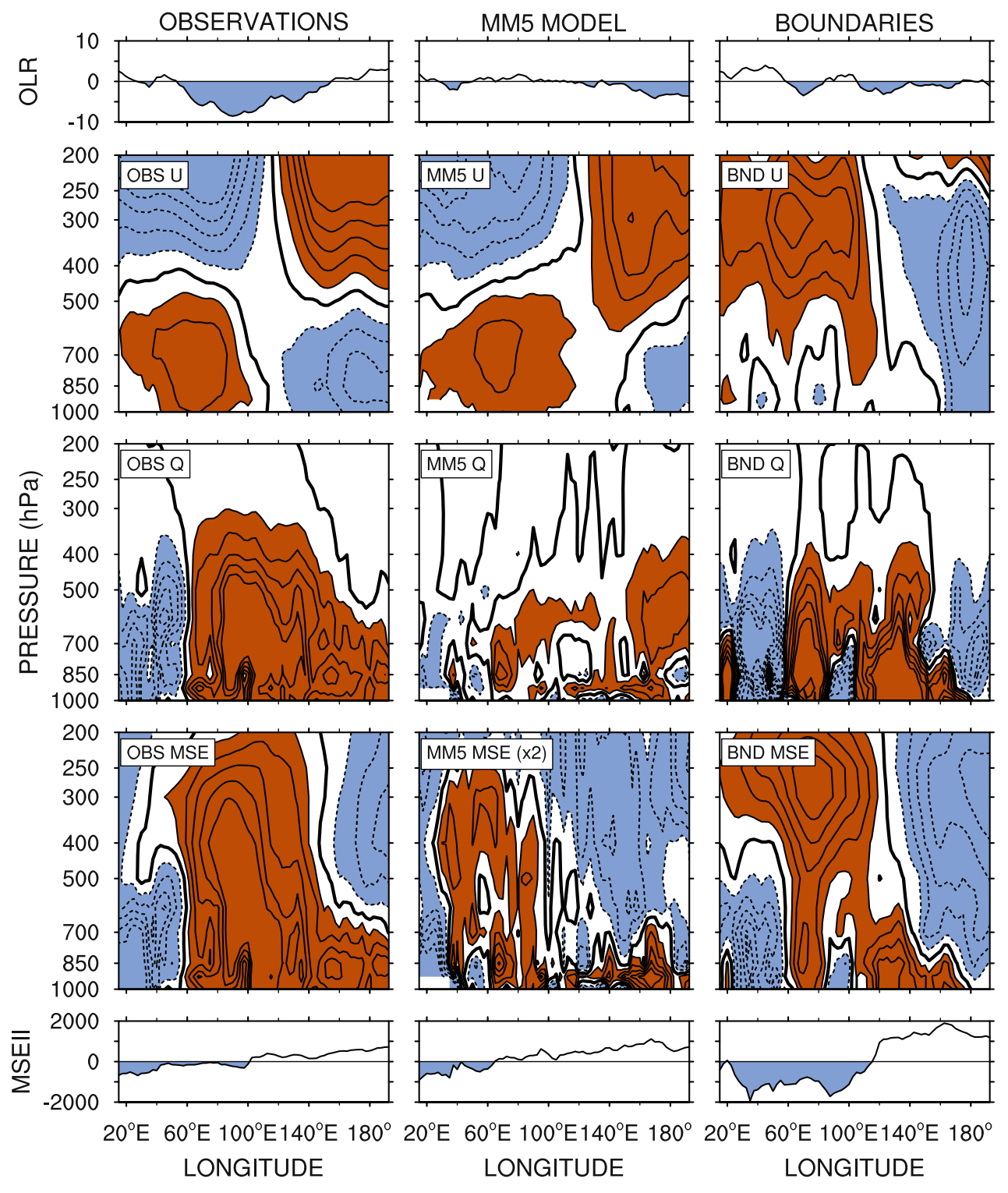

explanation for the inadequate simulation of the free atmosphere moisture could be the lack of convection over the Maritime Continent, which was previously shown to block the eastward propagation of lower-level Kelvin waves associated with the MJO in a GCM (Inness and Slingo 2006). The orography of the islands can weaken or even extinguish the simulated MJO signal over and east of the Maritime Continent.

The systematic procedure described in Sect. 2.3 was also used, when possible, to analyze the simulation presented in Gustafson and Weare (2004)(not shown). The results reveal similar features with leading modes presenting a strong MJO signal in the winds but not in the OLR. They also show weak eastward propagation in the thermodynamical fields in the Indian Ocean and stationary patterns in the Pacific Ocean. However, the intraseasonal signals in the moisture, OLR and precipitation tend to be more organized than in the ERA-40 simulation, especially over the Pacific Ocean. Overall, both MM5 runs show clear MJO signals in the circulation but no wind-convection coupling. This indicates that the choice of the input data and the addition of the African Continent to the MM5 domain does not substantially modify the simulation of the MJO.

Again, the MM5 has the ability to produce a realistic MJO phase speed in the zonal winds without simulating a proper MJO in the convection, precipitation and free atmosphere moisture. As seen in other studies, it is common to have models producing strong MJO signals in the winds but weaker ones in the precipitation (Zhang et al. 2006). This only implies that strong MJO signals in the circulation do not necessarily induce strong MJO signals in the convection. This study suggests that an MJO in the winds, with correct propagation features, can exist with 
Fig. 7 Hovmöller diagrams of 30-90 day bandpass filtered U200 averaged over $20^{\circ} \mathrm{S}-$ $20^{\circ}$ N. Each Hovmöller diagram is normalized by its maximum value. Dashed lines and solid thin lines represent respectively negative and positive values
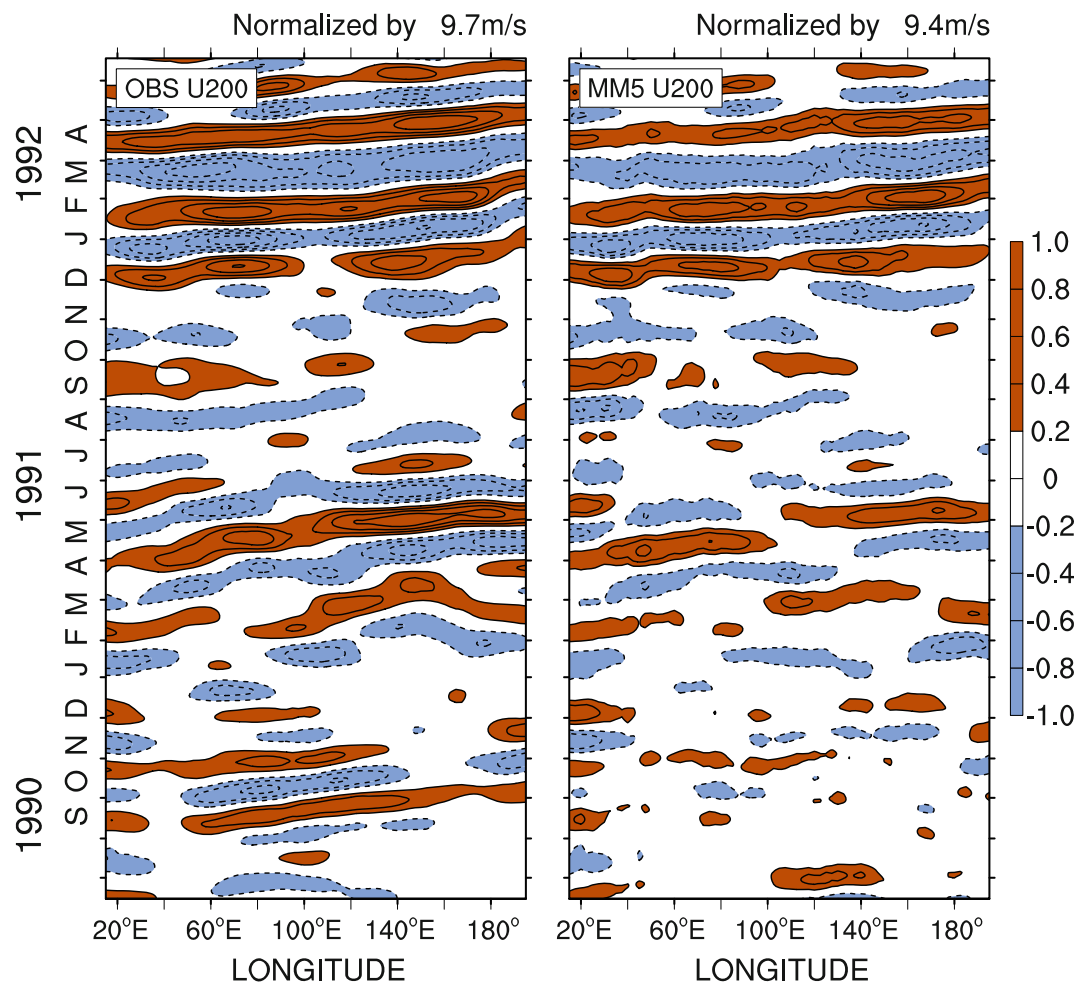
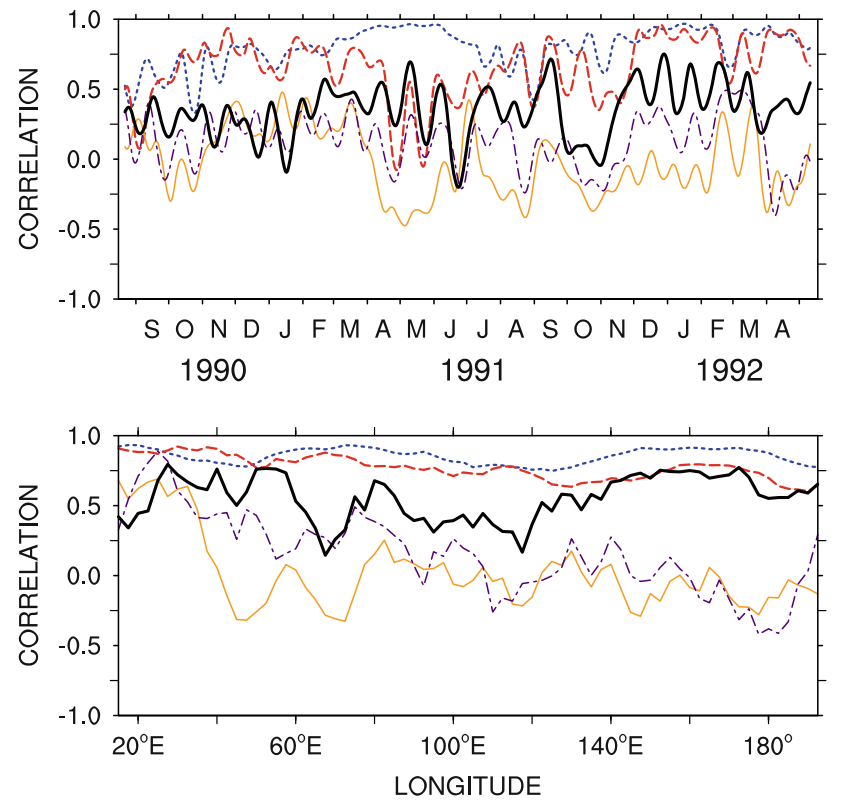

Fig. 8 Longitudinal correlations at all times (top) and temporal correlations at all longitudes (bottom) between the observations and the model output Hovmöller diagrams of 30-90 day bandpass filtered OLR (thin solid lines), U850 (dashed lines), U200 (dotted lines), Q850 (dot-dashed lines) and MSEII (thick solid lines) averaged over $20^{\circ} \mathrm{S}-20^{\circ} \mathrm{N}$

little or no MJO signal in the convection. The systematic analysis of the model output allows us to propose possible explanations. The first potential cause is the possibility that the MJO signal within the domain is simply forced by the
MJO present on the boundary conditions. The analysis of the MJO signal on the meridional boundaries reveals the absence of a realistic MJO propagation and vertical structure in phase with the signal in the model domain in the zonal winds and moisture. Thus we can conclude that the realistic MJO phase speed in the zonal winds is not directly controlled by an MJO signal entering the model domain through the meridional boundaries. This outcome corroborates the results of Ray et al. (2009) who, using a Tropical Channel MM5, show that changing the latitudinal locations of the meridional boundaries from 21 to $38^{\circ} \mathrm{NS}$ does not significantly alter the initiation and speed of propagation of the simulated MJO. Since there is no MJO-associated Kelvin component at $38^{\circ}$ latitudes, they conclude that the critical signal in the lateral boundary that forces the MJO represents extratropical influences instead of the MJO itself. Meanwhile, the western boundary influence is limited to the African Continent in the OLR and moisture field so it is doubtful that it could explain the propagation of the winds over the whole domain. Although it is possible that an extratropical forcing and circumnavigating waves participate in the organization of the MJO, it is unlikely that they solely explain the realistic signal found in the model output winds. Indeed, since the absence of moisture in a model results in signals propagating too fast (Lin et al. 2007; Ray et al. 2009), the role of moisture is undeniable. While the MM5 model does not produce a clear MJO signal in the free troposphere water vapor, it displays a strong MJO signal in the boundary layer moisture and in 
the moist static energy instability index which propagate at a realistic MJO phase speed. The results here suggest that the discharge and recharge of the moist static energy instability index and the convergence of boundary layer moisture may be responsible for controlling the speed of propagation of the MJO circulation. This conclusion is consistent with the findings of Kemball-Cook and Weare (2001), who propose to integrate the discharge-recharge hypothesis (Blade and Hartmann 1993) with the frictional wave-CISK theory (Salby et al. 1994) to allow a more complete view of the physics of the MJO.

This study suggests that deep convection is not a fundamental feature controlling the speed of propagation of the MJO in the winds but simply a by-product of the MJO mechanism. The dominating factors seem to be boundary layer moisture convergence, lower-level moist static energy building upward in the free troposphere and a discharge and recharge of the moist static energy instability index. For this reason, further MJO studies, especially when evaluating the realism of MJO simulations, should focus more on the coupling between the MJO circulation, atmospheric instability and boundary layer moisture processes. For example, the systematic analysis of upper- and lower-level winds and OLR could be extended to the moist static energy instability index used in this study. In addition, the analysis of the MJO energetics through MSE could be supplemented with a study of the convective available potential energy (CAPE) and diabatic heating profiles in subsequent projects. Also, further work should be done to better understand the role of the ocean in the MJO mechanism, in particular the impact of surface fluxes on the boundary layer moisture processes. For example, the MM5 model could be run coupled with an Ocean Model and a Land Surface Model and its simulated MJO could be compared to the present study. Similarly, the impact of planetary boundary layer parameterization on the realism of the MJO could be tested. Additionally, as computer limitations evolve, the length of the simulation could be extended to 5 or 10 years to obtain more robust statistics and nesting could be used to improve the model resolution over the Maritime Continent. Finally, the causes of the poor simulation of the MJO free atmosphere moisture could be investigated by calculating a moisture budget in order to identify the model deficiency. Knowing the source of the problem would help to know where the effort needs to go for model improvement.

Acknowledgments The authors want to thank Professor Chidong Zhang for his advice on this project, as well as the various anonymous reviewers for their comments and helpful discussions. ERA-40 data were provided by the European Centre for Medium-Range Weather Forecasts from their Web site at http://data.ecmwf.int/data/d/ era40_daily. Interpolated OLR data and CMAP Precipitation were provided by the NOAA/OAR/ESRL PSD, Boulder, Colorado, USA, from their Web site at http://www.cdc.noaa.gov. This study was partially supported by the National Science Foundation grant ATM0733698. Dr. Gustafson's portion of this manuscript has been authored by Battelle Memorial Institute, Pacific Northwest Division, under Contract No. DE-AC05-76RL01830 with the U.S. Department of Energy. The United States Government retains and the publisher, by accepting the article for publication, acknowledges that the United States Government retains a non-exclusive, paid-up, irrevocable, world-wide license to publish or reproduce the published form of this manuscript, or allow others to do so, for United States Government purposes.

Open Access This article is distributed under the terms of the Creative Commons Attribution Noncommercial License which permits any noncommercial use, distribution, and reproduction in any medium, provided the original author(s) and source are credited.

\section{References}

Annamalai H, Slingo JM, Sperber KR, Hodges K (1999) The mean evolution and variability of the Asian summer monsoon: comparison of ECMWF and NCEP-NCAR reanalyses. Mon Weather Rev 127(6):1157-1186. doi:10.1175/1520-0493(1999) $127<1157:$ TMEAVO $>2.0 . \mathrm{CO} ; 2$

Betts AK (1986) A new convective adjustement scheme. Part I: observational and theoretical basis. Quart J Roy Meteor Soc 112:677-691

Betts AK, Miller MJ (1986) A new convective adjustement scheme. Part II: single column tests using GATE wave, BOMEX, ATEX and arctic air-mass data sets. Quart J Roy Meteor Soc 112:693-709

Blade I, Hartmann DL (1993) Tropical intraseasonal oscillations in a simple nonlinear model. J Atmos Sci 50:2922-2939. doi: 10.1175/1520-0469(1993)050<2922:TIOIAS $>2.0$. CO;2

Boulanger JP, Menkes C, Lengaigne M (2004) Role of high-and lowfrequency winds and wave reflection in the onset, growth and termination of the 1997-1998 El Nino. Clim Dyn 22(2):267280. doi: $10.1007 / \mathrm{s} 00382-003-0383-8$

Duchon CE (1979) Lanczos filtering in one and two dimensions. J Appl Meteor 18:1016-1022. doi:10.1175/1520-0450(1979)018 $<1016$ :LFIOAT $>2.0 . \mathrm{CO} ; 2$

Grell GA, Dudhia J, Stauffer DR (1995) A description of the fifthgeneration Penn State/NCAR mesoscale model (MM5). NCAR Tech Note TN-398+ STR 122

Gustafson WI, Weare BC (2004) MM5 modeling of the MaddenJulian oscillation in the Indian and West Pacific Oceans: model description and control run results. J Clim 17:1320-1337. doi: 10.1175/1520-0442(2004)017<1320:MMOTMO > 2.0.CO;2

Hayashi Y (1982) Space-time spectral analysis and its applications to atmospheric waves. J Oceanogr Soc Jpn 60:156-171

Hendon HH, Glick J (1997) Intraseasonal air-sea interaction in the tropical Indian and Pacific Oceans. J Clim 10:647-661. doi: 10.1175/1520-0442(1997)010<0647:IASIIT>2.0.CO;2

Hendon HH, Salby ML (1994) The life cycle of the Madden-Julian oscillation. J Atmos Sci 51:2225-2237. doi:10.1175/1520-0469 (1994)051<2225:TLCOTM >2.0.CO;2

Hendon HH, Salby ML (1996) Planetary-scale circulations forced by intraseasonal variations of observed convection. J Atmos Sci 53(12):1751-1758. doi:10.1175/1520-0469(1996)053<1751: PSCFBI $>2.0 . \mathrm{CO} ; 2$

Hendon HH, Liebmann B, Newman M, Glick JD, Schemm JE (2000) Medium-range forecast errors associated with active episodes of the Madden-Julian oscillation. Mon Weather Rev 128(1):69-86. doi:10.1175/1520-0493(2000)128<0069:MRFEAW>2.0.CO;2 
Inness PM, Slingo JM (2006) The interaction of the Madden-Julian oscillation with the maritime continent in a GCM. Quart J Roy Meteor Soc 132:1645-1667. doi:10.1256/qj.05.102

Janjic ZI (1990) The step-mountain coordinate: physical package. Mon Weather Rev 118:1429-1443. doi:10.1175/1520-0493 (1990) $118<1429$ :TSMCPP $>2.0$. CO;2

Janjic ZI (1994) The step-mountain eta coordinate model: further developments of the convection, viscous sublayer, and turbulence closure schemes. Mon Weather Rev 122:927-945. doi: 10.1175/1520-0493(1994)122<0927:TSMECM >2.0.CO;2

Jones C (2000) Occurrence of extreme precipitation events in California and relationships with the Madden-Julian oscillation. J Clim 13:3576-3587. doi:10.1175/1520-0442(2000)013<3576: OOEPEI $>2.0 . \mathrm{CO} ; 2$

Jones C, Waliser DE, Gautier C (1998) The influence of the MaddenJulian oscillation on ocean surface heat fluxes and sea surface temperature. J Clim 11:1057-1072. doi:10.1175/1520-0442 (1998)011<1057:TIOTMJ >2.0.CO;2

Kemball-Cook SR, Weare BC (2001) The onset of convection in the Madden-Julian oscillation. J Clim 14:780-793. doi:10.1175/ 1520-0442(2001)014<0780:TOOCIT>2.0.CO;2

Kessler WS, Kleeman R (2000) Rectification of the Madden-Julian oscillation into the ENSO cycle. J Clim 13:3560-3575. doi: 10.1175/1520-0442(2000)013<3560:ROTMJO > 2.0.CO;2

Kiladis GN, Straub KH, Haertel PT (2005) Zonal and vertical structure of the Madden-Julian oscillation. J Atmos Sci 62:2790-2809. doi:10.1175/JAS3520.1

Lau KM, Chan PH (1986) Aspects of the 40-50 day oscillation during the northern summer as inferred from outgoing longwave radiation. Mon Weather Rev 114:1354-1367. doi:10.1175/ 1520-0493(1986)114<1354:AOTDOD>2.0.CO;2

Liebmann B, Smith CA (1996) Description of a complete (interpolated) outgoing longwave radiation dataset. Bull Am Meteor Soc $77: 1275-1277$

Lin H, Brunet G, Derome J (2007) Intraseasonal variability in a dry atmospheric model. J Atmos Sci 64:2422-2441. doi:10.1175/ JAS3955.1

Lin JL, Kiladis GN, Mapes BE, Weickmann KM, Sperber KR, Lin W, Wheeler MC, Schubert SD, Del Genio A, Donner LJ, Emori S, Gueremy JF, Hourdin F, Rasch PJ, Roeckner E, Scinocca JF (2006) Tropical intraseasonal variability in 14 IPCC AR4 climate models. Part I: convective signals. J Clim 19(12):2665-2690. doi: 10.1175/JCLI3735.1

Lin YL, Farley RD, Oville HD (1983) Bulk parameterization of the snow field in a cloud model. J Clim Appl Meteor 22:1065-1092. doi:10.1175/1520-0450(1983)022<1065:BPOTSF $>2.0 . C O ; 2$

Madden RA, Julian PR (1971) Detection of a 40-50 day oscillation in the zonal wind in the tropical pacific. J Atmos Sci 28:702-708. doi:10.1175/1520-0469(1971)028<0702:DOADOI >2.0.CO;2

Madden RA, Julian PR (1972) Description of Global-Scale Circulation Cells in Tropics with a 40-50 Day Period. J Atmos Sci 29:1109-1123. doi:10.1175/1520-0469(1972)029<1109:DOGSCC >2.0.CO;2

Madden RA, Julian PR (1994) Observations of the 40-50-day tropical oscillation-a review. Mon Weather Rev 122:814-837. doi: 10.1175/1520-0493(1994)122<0814:OOTDTO $>2.0 . C O ; 2$

Maloney ED, Hartmann DL (2000) Modulation of eastern north pacific hurricanes by the Madden-Julian oscillation. J Clim 13:1451-1460. doi:10.1175/1520-0442(2000)013<1451:MOENPH > 2.0.CO;2

Mlawer EJ, Taubman SJ, Brown PD, Iacono MJ, Clough SA (1997) Radiative transfer for inhomogeneous atmospheres: RRTM, a validated correlated-k model for the longwave. J Geophys Res 102:16663-16682. doi:10.1029/97JD00237

Newman M, Sardeshmukh PD, Bergman JW (2000) An assessment of the NCEP, NASA, and ECMWF reanalyses over the tropical west pacific warm pool. Bull Am Meteor Soc 81:41-48. doi: 10.1175/1520-0477(2000)081<0041:AAOTNN >2.3.CO;2
North GR, Bell TL, Cahalan RF, Moeng FJ (1982) Sampling errors in the estimation of empirical orthogonal functions. Mon Weather Rev 110:699-706. doi:10.1175/1520-0493(1982)110<0699: SEITEO $>2.0 . \mathrm{CO} ; 2$

Randall DA, Wood Ra, Bony S, Colman R, Fichefet T, Fyfe J, Kattsov V, Pitman A, Shukla J, Srinivasan J, Stouffer RJ, Sumi A, Taylor KE (2007) Climate models and their evaluation. In: Solomon S, Qin D, Manning M, Chen Z, Marquis M, Averyt KB, Tignor M, Miller HL (eds) Climate change 2007: the physical science basis. Contribution of Working Group I to the fourth assessment report of the Intergovernmental Panel on climate change, Cambridge University Press, Cambridge

Ray P, Zhang C, Dudhia J, Chen SS (2009) A numerical case study on the initiation of the Madden-Julian oscillation. J Atmos Sci 66(2):310-331. doi:10.1175/2008JAS2701.1

Salby ML, Hendon HH (1994) Intraseasonal behavior of clouds, temperature, and motion in the tropics. J Atmos Sci 51:2207-2224. doi:10.1175/1520-0469(1994)051<2207:IBOCTA>2.0.CO;2

Salby ML, Garcia RR, Hendon HH (1994) Planetary-scale circulations in the presence of climatological and wave-induced heating. J Atmos Sci 51(16):2344-2367. doi:10.1175/1520-0469 (1994) $051<2344$ :PSCITP $>2.0$. CO;2

Sperber KR (2003) Propagation and the vertical structure of the Madden-Julian oscillation. Mon Weather Rev 131:3018-3037. doi:10.1175/1520-0493(2003)131<3018:PATVSO > 2.0.CO;2

Tao WK, Simpson J, McCumber M (1989) A ice-water saturation adjustment. Mon Weather Rev 117:231-235. doi:10.1175/15200493(1989)117<0231:AIWSA > 2.0.CO;2

Uppala SM, Kallberg PW, Simmons AJ, Andrae U, Bechtold VD, Fiorino M, Gibson JK, Haseler J, Hernandez A, Kelly GA, Li X, Onogi K, Saarinen S, Sokka N, Allan RP, Andersson E, Arpe K, Balmaseda MA, Beljaars ACM, Van De Berg L, Bidlot J, Bormann N, Caires S, Chevallier F, Dethof A, Dragosavac M, Fisher M, Fuentes M, Hagemann S, Holm E, Hoskins BJ, Isaksen L, Janssen PAEM, Jenne R, McNally AP, Mahfouf JF, Morcrette JJ, Rayner NA, Saunders RW, Simon P, Sterl A, Trenberth KE, Untch A, Vasiljevic D, Viterbo P, Woollen J (2005) The ERA-40 re-analysis. Quart J Roy Meteor Soc 131:2961-3012. doi:10.1256/qj.04.176

Weare BC (2003) Composite singular value decomposition analysis of moisture variations associated with the Madden-Julian oscillation. J Clim 16:3779-3792. doi:10.1175/1520-0442(2003) 016<3779:CSVDAO $>2.0 . \mathrm{CO} ; 2$

Weare BC (2006) Centered composite analysis of variations associated with the Madden-Julian oscillation. J Clim 19:1834-1849. doi:10.1175/JCLI3703.1

Wheeler MC, Hendon HH (2004) An all-season real-time multivariate MJO index: development of an index for monitoring and prediction. Mon Weather Rev 132:1917-1932. doi:10.1175/ 1520-0493(2004)132<1917:AARMMI>2.0.CO;2

Xie PP, Arkin PA (1997) Global precipitation: a 17-year monthly analysis based on gauge observations, satellite estimates, and numerical model outputs. Bull Am Meteor Soc 78:2539-2558. doi:10.1175/1520-0477(1997)078<2539:GPAYMA >2.0.CO;2

Zhang C (1996) Atmospheric intraseasonal variability at the surface in the tropical western Pacific Ocean. J Atmos Sci 53:739-758. doi:10.1175/1520-0469(1996)053<0739:AIVATS > 2.0.CO;2

Zhang C (2005) Madden-Julian oscillation. Rev Geophys 43:RG2003. doi:10.1029/2004RG000158

Zhang C, Hendon HH (1997) Propagating and standing components of the intraseasonal oscillation in tropical convection. J Atmos Sci 54:741-752. doi:10.1175/1520-0469(1997)054<0741: PASCOT $>2.0 . \mathrm{CO} ; 2$

Zhang C, Dong M, Gualdi S, Hendon HH, Maloney ED, Marshall A, Sperber KR, Wang W (2006) Simulations of the Madden-Julian oscillation in four pairs of coupled and uncoupled global models. Clim Dyn 27:573-592. doi:10.1007/s00382-006-0148-2 